\title{
Perfil epidemiológico da infecção por COVID-19 em receptores de transplante renal de um centro do nordeste do Brasil e fatores preditivos de mortalidade
}

\author{
Epidemiological profile of COVID-19 infection in kidney transplantation recipients from a center \\ of northeastern Brazil and predictive factors of mortality \\ Perfil epidemiológico de la COVID-19 infección en receptores de trasplante renal de un centro del \\ noreste de Brasil y factores predictivos de mortalidad
}

Tamye Zimmermann D'Agnoluzzo ORCID: https://orcid.org/0000-0002-0963-3061 Universidade Federal do Ceará, Brasil E-mail: tamyenefro@gmail.com Aline Lima Cunha Alcântara ORCID: https://orcid.org/0000-0001-5010-798X Universidade Federal do Ceará, Brasil E-mail: liny_cunha@yahoo.com.br

Paula Frassinetti Castelo Branco Camurça Fernandes ORCID: https://orcid.org/0000-0002-7442-301X Universidade Federal do Ceará, Brasil E-mail: paulafcbcfernandes@yahoo.com Evelyne Santana Girão ORCID: https://orcid.org/0000-0003-3059-5490 Universidade Federal do Ceará, Brasil E-mail: egirao@uol.com.br

Tainá Veras de Sandes Freitas ORCID: https://orcid.org/0000-0002-4435-0614 Universidade Federal do Ceará, Brasil E-mail: taina.sandes@gmail.com

Claudia Maria Costa de Oliveira ORCID: https://orcid.org/0000-0002-2795-6681 Universidade Federal do Ceará, Brasil E-mail: claudiadrl@gmail.com.

\begin{abstract}
Resumo
Objetivos: Investigar a mortalidade por COVID-19 em receptores de transplante renal (TR) e os fatores associados ao maior risco de óbito. Métodos: Os receptores de TR com suspeita de COVID-19 foram monitorados por nefrologistas de março a dezembro de 2020, através de contato telefônico diário, sendo registrados dados clinico-laboratoriaisevolutivos referentes à COVID-19. Uma análise multivariada (regressão logística, forward stepwise) para pesquisa de fatores preditivos de óbito foi realizada. Resultados: Foram confirmados 96 casos de COVID-19 (RT-PCR ou sorologia COVID), sendo 55,2\% masculino, idade média 49,1 anos, 90,6\% doador falecido e mediana do tempo de TR de 5,2 anos. As comorbidades mais frequentes foram HAS (76\%), diabetes $(37,5 \%)$ e doença cardiovascular $(14,6 \%)$. A imunossupressão mais utilizada foi tacrolimo/micofenolato (66,7\%) e prednisona (69,8\%). Em 39,6\% dos casos foi necessário internamento, sendo 18,8\% em UTI. Em relação aos desfechos, 87,5\% ficaram livres da doença e $12,5 \%$ foram a óbito. Na análise multivariada, associaram-se à maior chance de óbito: o tempo de transplante superior a 5,7 anos e a idade do receptor superior a 55 anos, enquanto uma menor creatinina basal associou-se à menor chance de mortalidade Conclusão: A mortalidade por COVID-19 em receptores de TR foi superior à da população geral, mas inferior ao descrito em outros centros de transplante. O tempo de transplante e a idade do receptor foram preditivos de óbito nesta população, enquanto uma menor creatinina basal associou-se à menor mortalidade.
\end{abstract}

Palavras-chave: Transplante de rim; Infecções por coronavírus; Mortalidade.

\begin{abstract}
Objectives: To investigate mortality from COVID-19 in renal transplant recipients (RT) and factors associated with increased risk of death. Methods: RT recipients with suspected COVID-19 were monitored by nephrologists from march to december 2020, through daily telephone contact, and clinical-laboratory-evolution data regarding COVID19 were recorded. A multivariate analysis (logistic regression, forward stepwise) to search for predictive factors of death was performed. Results: 96 cases of COVID-19 were confirmed (RT-PCR or COVID serology), being 55.2\%
\end{abstract}


male, mean age 49.1 years, $90.6 \%$ deceased donor and median RT time 5.2 years. The most frequent comorbidities were SAH (76\%), diabetes (37.5\%) and cardiovascular disease $(14.6 \%)$. The most used immunosuppression was tacrolimus/mycophenolate $(66.7 \%)$ and prednisone $(69.8 \%)$. In $39.6 \%$ of the cases, hospitalization was necessary, with $18.8 \%$ in the ICU. Regarding the outcomes, $87.5 \%$ were free of the disease and $12.5 \%$ died. In the multivariate analysis, the following variables were associated with a greater chance of death: time since transplantation greater than 5.7 years and recipient age greater than 55 years, while a lower baseline creatinine was associated with a lower chance of mortality. Conclusion: Mortality by COVID-19 in RT recipients was higher than in the general population, but lower than that described in other transplant centers. Transplant time and recipient age were predictors of death in this population, while lower baseline creatinine was associated with lower mortality.

Keywords: Kidney transplantation; Novel coronavirus infection; Mortality.

\section{Resumen}

Objetivos: Investigar la mortalidad por COVID-19 en receptores de trasplante renal (TR) y los factores asociados con un mayor riesgo de muerte. Métodos: Los receptores de TR con sospecha de COVID-19 fueron monitoreados por nefrólogos desde marzo a diciembre de 2020, mediante contacto telefónico diario, y se registraron datos clínicolaboratorio-evolutivos sobre COVID-19. Se realizó un análisis multivariado (regresión logística, avance por pasos) para buscar factores predictivos de muerte. Resultados: Se confirmaron 96 casos de COVID-19 (RT-PCR o serología COVID), siendo 55,2\% varones, edad media 49,1 años, 90,6\% donante fallecido y mediana de tiempo de RT de 5,2 años. Las comorbilidades más frecuentes fueron HSA (76\%), diabetes $(37,5 \%)$ y enfermedad cardiovascular $(14,6 \%)$. La inmunosupresión más utilizada fue tacrolimus/micofenolato $(66,7 \%)$ y prednisona $(69,8 \%)$. En el 39,6\% de los casos fue necesaria la hospitalización, con el 18,8\% en cuidados intensivos. En cuanto a los resultados, el 87,5\% estaban libres de la enfermedad y el 12,5\% falleció. En el análisis multivariado, los siguientes se asociaron con una mayor probabilidad de muerte: tiempo desde el trasplante mayor de 5,7 años y edad del receptor mayor de 55 años, mientras que una menor creatinina basal se asoció con una menor probabilidad de mortalidad. Conclusión: Mortalidad por COVID -19 en los receptores de TR fue mayor que en la población general, pero menor que la descrita en otros centros de trasplante. El tiempo de trasplante y la edad del receptor fueron predictores de muerte en esta población, mientras que una creatinina basal más baja se asoció con una mortalidad más baja.

Palabras clave: Trasplante de riñón; Infección por nuevo coronavirus; Mortalidad.

\section{Introdução}

A COVID-19 é uma doença respiratória altamente infecciosa causada pelo novo coronavírus, conhecido como SARSCoV-2 (Wang et al., 2021). Em 30 de janeiro de 2020, a epidemia de COVID-19 foi declarada pela OMS como uma emergência de saúde pública de preocupações internacionais (Mitchell, 2020).

O transplante renal é o tratamento de escolha para a maioria dos pacientes com doença renal crônica terminal (Voora \& Adev, 2019). Atualmente, o Brasil ocupa terceiro lugar no mundo em número de transplantes e possui o maior nível de financiamento público para esse procedimento (Pêgo-Fernandes et al., 2019).

Os receptores de transplante renal parecem estar em risco particularmente alto de COVID-19 grave. O consenso geral a respeito da suscetibilidade viral em receptores de transplantes é que indivíduos imunocomprometidos apresentam maior risco de infecção grave devido às respostas imunológicas prejudicadas, particularmente na presença de comorbidades concomitantes, que são amplamente comuns em pacientes com doença renal crônica (Elias et al., 2020).

Segundo Gonzalez e Ciancio (2020), o manejo ideal dos pacientes receptores de transplante renal ainda está em debate e a abordagem terapêutica ainda carece de evidências significativas, além do manejo dos imunossupressores ser desafiador, representando um equilíbrio delicado entre o controle da infecção e a função do enxerto.

Através do consenso italiano, Vistoli et al. (2020) recomendam que os pacientes transplantados renais infectados pelo SARS-CoV-2 nos quais a internação pode ser evitada, devem ser acompanhados remotamente. Durante a pandemia de COVID-19, programas remotos de consulta a especialistas devem ser estabelecidos pelas agências centrais de transplante, para auxiliar centros únicos nas difíceis decisões de manejo ambulatorial de receptores. 


\section{Metodologia}

Trata-se de um estudo de coorte prospectivo, observacional, descritivo, de único centro, através do seguimento de receptores de transplante renal entre os meses de março a dezembro de 2020. A pesquisa foi aprovada no Comitê de Ética em Pesquisa da Universidade Federal do Ceará sob o número 2.174.880.

Foram incluídos os receptores de transplante renal do Hospital Universitário Walter Cantídio/UFC que tiveram o diagnóstico de infecção por SARS-CoV-2, no período acima mencionado. O diagnóstico de COVID-19 foi aceito para pacientes que apresentavam sintomas suspeitos para COVID-19 associado a um dos seguintes testes positivos: RT-PCR ou sorologia. Foram excluídos os casos prováveis ou possíveis, nos quais não havia comprovação laboratorial, bem como pacientes que já haviam perdido a função do enxerto e migrados para outro tipo de terapia renal substitutiva antes do diagnóstico de COVID-19.

Os pacientes com sinais e sintomas sugestivos da doença foram seguidos por uma nefrologista do hospital através de teleconsulta, onde foram registrados dados demográficos os receptores, dados do transplante e variáveis relacionadas à COVID-19. No caso de internação, houve contato diário por telefone com a equipe assistencial para registro dos dados.

As variáveis pesquisadas foram: características demográficas dos receptores; presença de comorbidades; tipo de doador; tempo de TRS e tempo de transplante; esquema de imunossupressão em uso; quadro clínico; métodos diagnósticos; tratamento instituído e alteração no esquema de imunossupressão; desfechos da infecção.

Foram calculadas as medidas estatísticas descritivas como frequência, porcentagem, médias e desvio padrão para as variáveis quantitativas. Uma análise multivariada (regressão logística, forward stepwise) para pesquisa de fatores preditivos de óbito por COVID-19, durante a evolução inicial da doença, foi realizada. Para a análise dos dados foi utilizado o software estatístico SPSS 20.0, licença número 10101131007.

\section{Resultados}

No período do estudo, entre 1150 pacientes em seguimento ativo, o centro de transplantes teve conhecimento de 96 pacientes com o diagnóstico de infecção por SARS-CoV-2, sendo 53 do sexo masculino (55,2\%), idade média de 49,1 $\pm 13,8$ anos (variando de 23 a 83 anos). As principais causas de doença renal primária foram indeterminada (30,2\%), glomerulopatias $(28,1 \%)$, nefropatia diabética $(14,6 \%)$, doença renal policística $(10,4 \%)$ e hipertensão arterial $(5,2 \%)$. O tempo médio de transplante no diagnóstico da COVID-19 foi de 8,1 \pm 7,7 anos (mediana: 6,1; variação: 0,09 a 35,5 anos) e o doador foi falecido em 87 casos $(90,6 \%)$.

A distribuição do início dos sintomas de COVID-19 ao longo do tempo de seguimento encontra-se na Figura 1. 
Figura 1. Distribuição do início de sintomas de COVID-19 na população em estudo ao longo do tempo de seguimento.

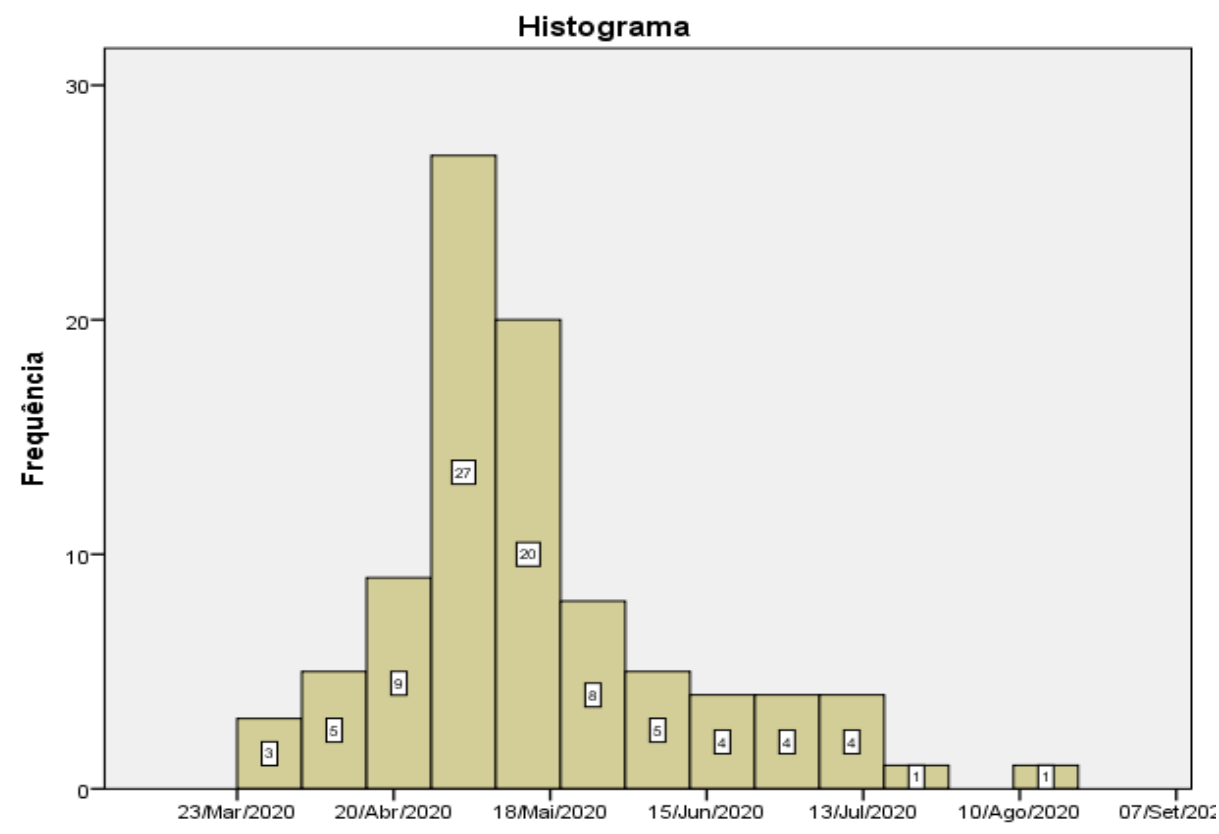

Fonte: Elaborada pelos autores.

As principais comorbidades dos receptores de transplante com COVID-19 foram a hipertensão arterial sistêmica (HAS) $(\mathrm{n}=73 ; 76 \%)$, seguida por diabetes mellitus $(\mathrm{DM})(\mathrm{n}=36 ; 37,5 \%)$. Entre os pacientes, 25\% faziam uso de iECA/BRA no momento do diagnóstico e $25 \%$ relatavam tabagismo atual ou pregresso. No momento do diagnóstico de SARS-CoV-2, 69,8\% dos pacientes fazia uso de prednisona e o principal regime imunossupressor utilizado era a associação de tacrolimo e micofenolato (66,7\%), seguido de tacrolimo e inibidor da mTOR (19,8\%). Além disso, nos três meses que antecederam ao diagnóstico de COVID-19, cinco pacientes haviam recebido metilprednisolona e timoglobulina. Na Tabela 1, as características clínico-demográficas na população em estudo estão demonstradas. 
Tabela 1. Características clínico-demográficas dos receptores de transplante renal com COVID-19 no período do estudo.

\begin{tabular}{|c|c|}
\hline Total $(n=96)$ & N (Percentual) \\
\hline \multicolumn{2}{|l|}{ Gênero } \\
\hline Feminino & $43(44,8 \%)$ \\
\hline Masculino & $53(55,2 \%)$ \\
\hline \multicolumn{2}{|l|}{ Tipo de doador } \\
\hline Doador vivo & $9(9,4 \%)$ \\
\hline Doador falecido & $87(90,6 \%)$ \\
\hline \multicolumn{2}{|l|}{ Raça } \\
\hline Branca & $20(20,8 \%)$ \\
\hline Parda & $65(67,7 \%)$ \\
\hline Negra & $7(7,3 \%)$ \\
\hline Outras & $4(4,8 \%)$ \\
\hline \multicolumn{2}{|l|}{ Doença renal primária } \\
\hline Indeterminada & $29(30,2 \%)$ \\
\hline Glomerulopatias & $27(28,1 \%)$ \\
\hline Nefropatia diabética & $14(14,6 \%)$ \\
\hline Doença renal policística & $10(10,4 \%)$ \\
\hline Hipertensão arterial & $5(5,2 \%)$ \\
\hline Outras & $6(6,3 \%)$ \\
\hline Tabagismo sim & $24(25,0 \%)$ \\
\hline Uso de IECA/BRA sim & $24(25,0 \%)$ \\
\hline Comorbidades sim & $86(89,6 \%)$ \\
\hline Hipertensão Arterial & $73(76,0 \%)$ \\
\hline Diabetes Mellitus & $36(37,5 \%)$ \\
\hline Doença cardiovascular & $14(14,6 \%)$ \\
\hline Neoplasia & $12(12,5 \%)$ \\
\hline Obesidade & $22(22,9 \%)$ \\
\hline Outras & $29(30,2 \%)$ \\
\hline \multicolumn{2}{|l|}{ Imunossupressão no COVID-19 } \\
\hline Tacrolimo + Micofenolato & $64(66,7 \%)$ \\
\hline Tacrolimo + inibidor mTOR & $19(19,8 \%)$ \\
\hline Outros & $13(13,5 \%)$ \\
\hline Prednisona & $67(69,8 \%)$ \\
\hline Variável & Média \pm Desvio padrão \\
\hline Idade & $49,1 \pm 13,8$ anos \\
\hline Tempo de Transplante no COVID-19 & $7,75 \pm 7,98$ anos (mediana: 5,17 ) \\
\hline $\operatorname{IMC}\left(\mathrm{Kg} / \mathbf{m}^{2}\right)$ & $25,6 \pm 5,21$ \\
\hline
\end{tabular}

As principais manifestações clínicas da COVID-19 nos receptores de transplante renal estão apresentadas na Tabela 2. Os exames laboratoriais dos pacientes em estudo no diagnóstico da COVID-19 encontram-se na Tabela 3. 
Tabela 2. Frequência das principais manifestações clínicas ao diagnóstico da COVID-19 nos receptores de transplante renal em estudo.

\begin{tabular}{cc}
\hline Manifestação clínica & N (Percentual) \\
\hline Febre & $63(65,6 \%)$ \\
Tosse & $60(62.5 \%)$ \\
Mialgia & $39(40,6 \%)$ \\
Diarreia & $33(34,4 \%)$ \\
Cefaleia & $32(33,3 \%)$ \\
Anosmia & $24(25,0 \%)$ \\
Fadiga & $23(24,0 \%)$ \\
Dispneia & $22(22,9 \%)$ \\
Ageusia & $18(18,8 \%)$ \\
Dor torácica & $14(14,6 \%)$ \\
Náuseas/vômitos & $14(14,6 \%)$ \\
Coriza & $12(12,5 \%)$ \\
Odinofagia & $12(12,5 \%)$ \\
Hiporexia & $11(11,5 \%)$ \\
Expectoração & $10(10,4 \%)$ \\
Calafrios & $07(7,3 \%)$ \\
\hline
\end{tabular}

Fonte: Elaborada pelos autores.

Tabela 3. Exames laboratoriais dos pacientes em estudo no diagnóstico da COVID-19.

\begin{tabular}{lccc}
\hline Exame & $\mathbf{N}$ & Média \pm Desvio Padrão (Mediana) & Variação \\
\hline Hemoglobina (g/dl) & 63 & $12 \pm 2(12,1)$ & $7,6-18,3$ \\
Linfócitos $\left(\mathbf{m m}^{\mathbf{3}}\right)$ & 66 & $1039 \pm 776(792,5)$ & $115-3680$ \\
Plaquetas $\left(\mathbf{m m}^{3}\right)$ & 64 & $191.630 \pm 80.187(193.500)$ & $15.300-475.000$ \\
PCR (mg/L) & 52 & $32,6 \pm 63(6,85)$ & $0,04-323$ \\
LDH (U/L) & 52 & $529 \pm 432(430,5)$ & $136-3318$ \\
CPK (U/L) & 41 & $190,9 \pm 472(55)$ & $0,03-2815$ \\
TGO (U/L) & 58 & $48 \pm 44(32)$ & $11-196$ \\
TGP (U/L) & 58 & $43 \pm 40(35)$ & $9-266$ \\
Creatinina basal (mg/dL) & 95 & $1,5 \pm 1,1(1,40)$ & $0,7-10,2$ \\
Creatinina atual (mg/dL) & 63 & $1,8 \pm 1(1,60)$ & $0,7-5,8$ \\
Sódio sérico (mEq/L) & 53 & $135 \pm 6,2(136)$ & $111-143$ \\
Troponina (ng/L) & 18 & $0,49 \pm 0,7(0,20)$ & $0-2,59$ \\
D-dímero (ng/mL) & 23 & $2,5 \pm 2,8(1,67)$ & $0,27-9,73$ \\
Ferritina (ng/mL) & 39 & $898 \pm 956(529)$ & $27-5166$ \\
Fibrinogênio (mg/dL) & 17 & $487 \pm 160(484)$ & $287-775$ \\
\hline
\end{tabular}

Fonte: Elaborada pelos autores.

A maioria dos pacientes foi submetida a testes diagnósticos para SARS-CoV-2 devido suspeita clínica (n=88; 91,6\%), enquanto 8 pacientes estavam assintomáticos no momento do diagnóstico, sendo 4 diagnosticados devido rastreio durante internação e outros 4 pacientes através de rastreio ambulatorial. A principal fonte de contágio foi a comunitária (90,6\% dos pacientes) e a transmissão foi nosocomial em 9,4\% dos casos. A confirmação diagnóstica foi realizada por RT-PCR em 35 receptores $(36,4 \%)$ e sorologia para SARS-CoV-2 em 65 casos $(67,7 \%)$.

A tomografia computadorizada (TCAR) de tórax foi realizada em 55 pacientes $(87,3 \%)$, com sinais radiológicos de algum acometimento pulmonar em 96,4\% dos pacientes que fizeram o exame, sendo a presença de vidro fosco a principal alteração detectada (Figura 2). 
Figura 2. Distribuição das principais alterações radiológicas detectadas na tomografia de tórax dos receptores de transplante renal em estudo $(n=55)$.

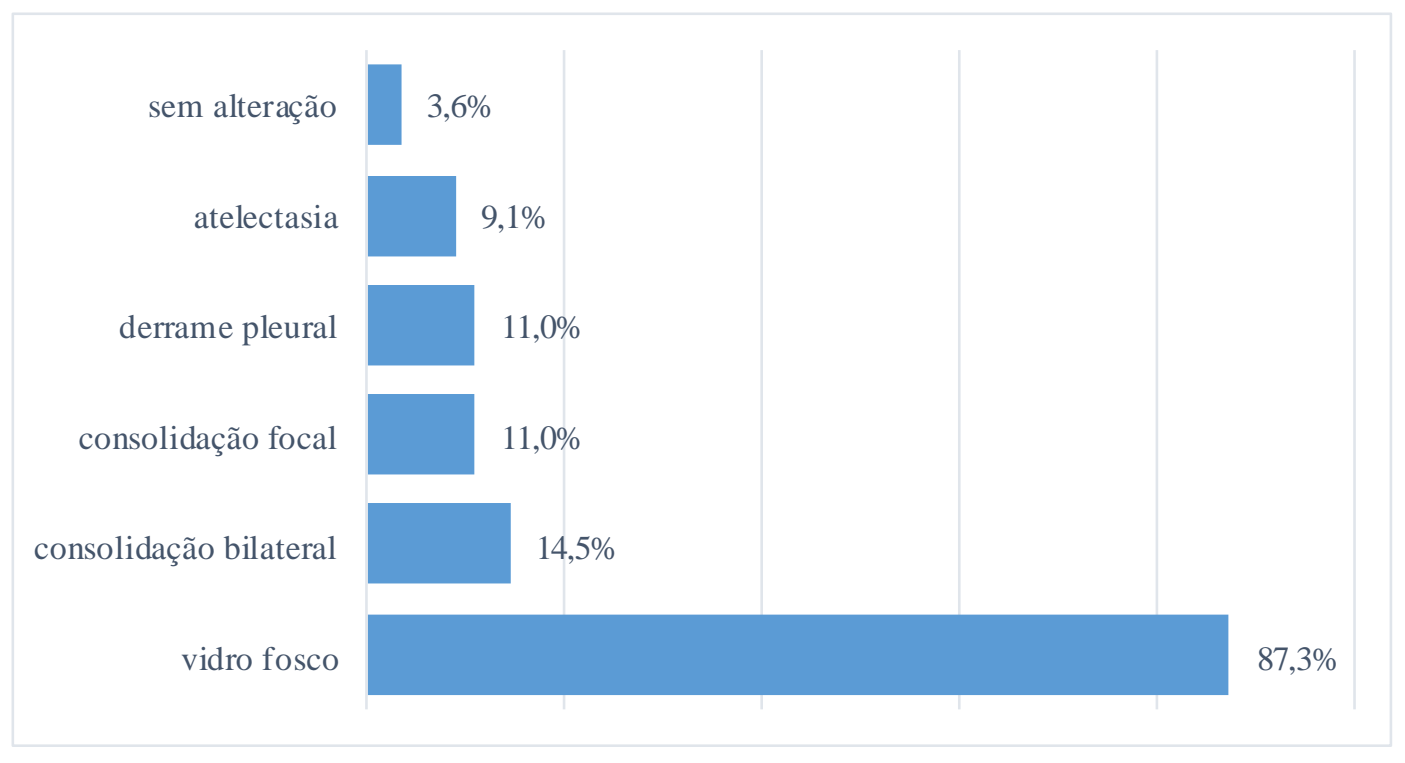

Fonte: Elaborada pelos autores.

Os principais medicamentos utilizados no tratamento da COVID-19 nos receptores de transplante renal em estudo encontram-se na Figura 3. A azitromicina foi o medicamento mais prescrito $(69,8 \%$ dos pacientes), seguido pelos esteroides $(52,1 \%)$ e ivermectina $(36,5 \%)$. Em geral, 57,3\% $(n=55)$ dos pacientes apresentaram suspeita ou confirmação de coinfecção, sendo as infecções respiratórias as mais comuns e antibióticos foram prescritos em 34,4\% dos casos.

Figura 3. Principais medicamentos utilizados no tratamento da COVID-19 nos receptores de transplante renal em estudo.

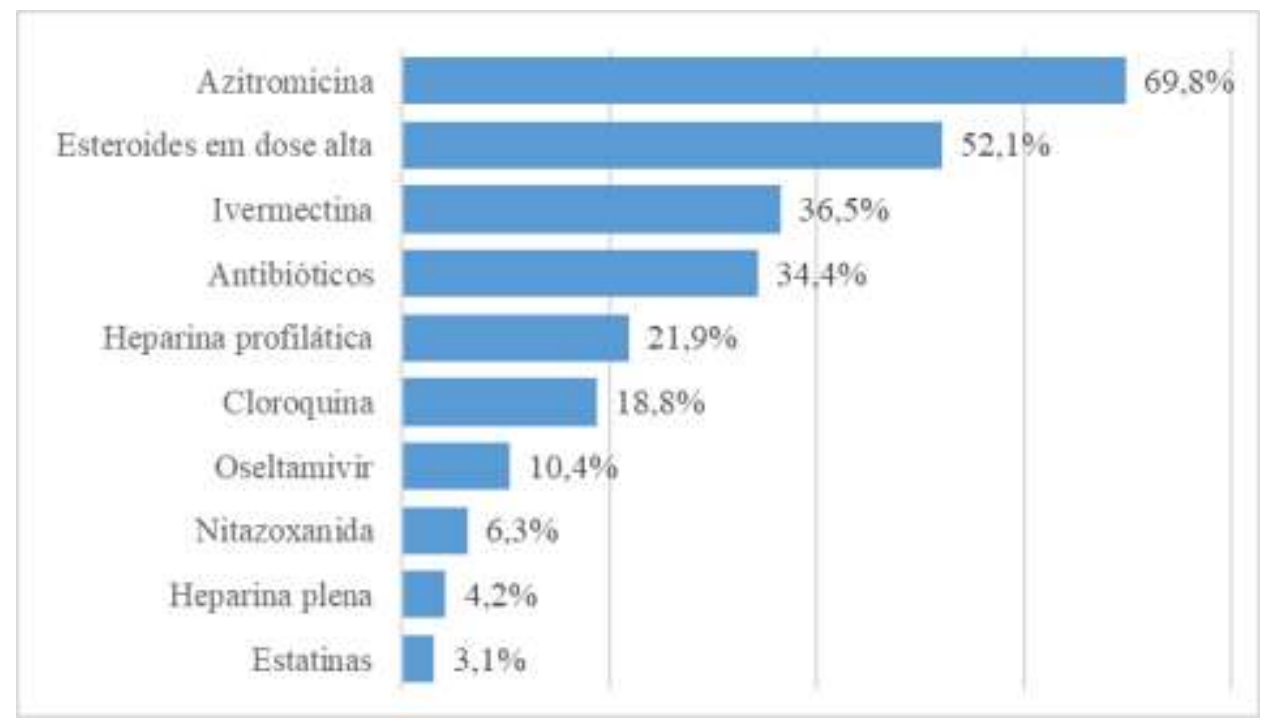

Fonte: Elaborada pelos autores.

Os receptores de transplante renal com COVID-19 permaneceram com o esquema imunossupressor habitual em $40,6 \%$ dos casos. As principais mudanças no esquema imunossupressor durante a infecção foram a redução (21,9\% dos casos) ou a suspensão completa $(29,2 \%$ dos casos) do medicamento antiproliferativo. A suspensão completa dos imunossupressores ocorreu em 8,3\% dos pacientes (Figura 4). 
Figura 4. Manejo da imunossupressão dos pacientes transplantados renais com diagnóstico de infecção pelo SARS-CoV-2.

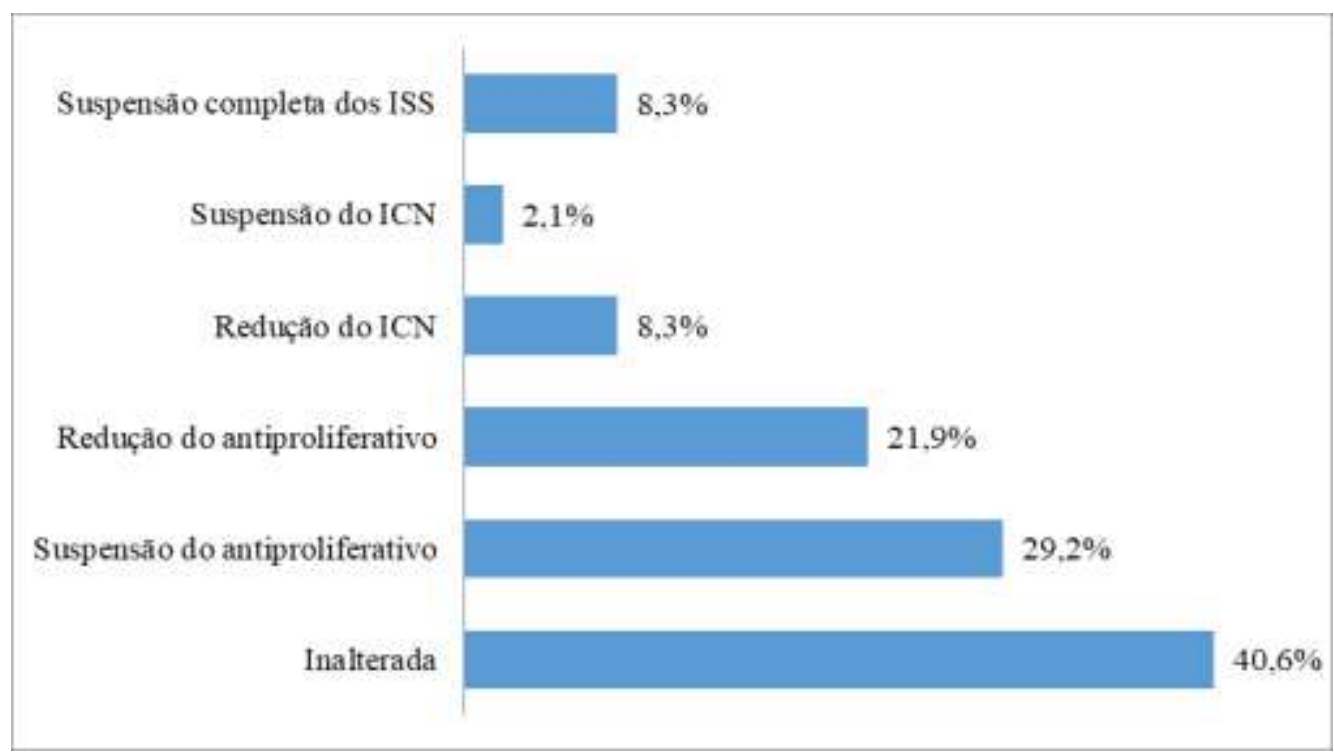

ICN: inibidor da calcineurina; ISS: imunossupressores. Fonte: Elaborada pelos autores.

A maioria dos pacientes com diagnóstico de COVID-19 apresentou doença sintomática, sendo que somente 6,2\% dos mesmos cursou com infecção assintomática. Houve necessidade de internação em 39,6\% dos casos e s internação foi em terapia intensiva em 18,8\%. Entre os pacientes internados em UTI, 6,3\% foram internados à admissão e 12,5\% transferidos para a UTI durante a evolução da internação. Um total de $15,6 \%$ dos pacientes necessitou de ventilação mecânica $(6,3 \%$ dos pacientes com pronação e 9,4\% sem pronação). Insuficiência renal durante a COVID-19, com indicação de terapia renal substitutiva, ocorreu em 10,4\% dos casos. A evolução ao óbito foi observada em 12,5\% dos casos (Figura 5).

Figura 5. Evolução clínica da infecção por SARS-CoV-2 nos receptores de transplante renal em estudo.

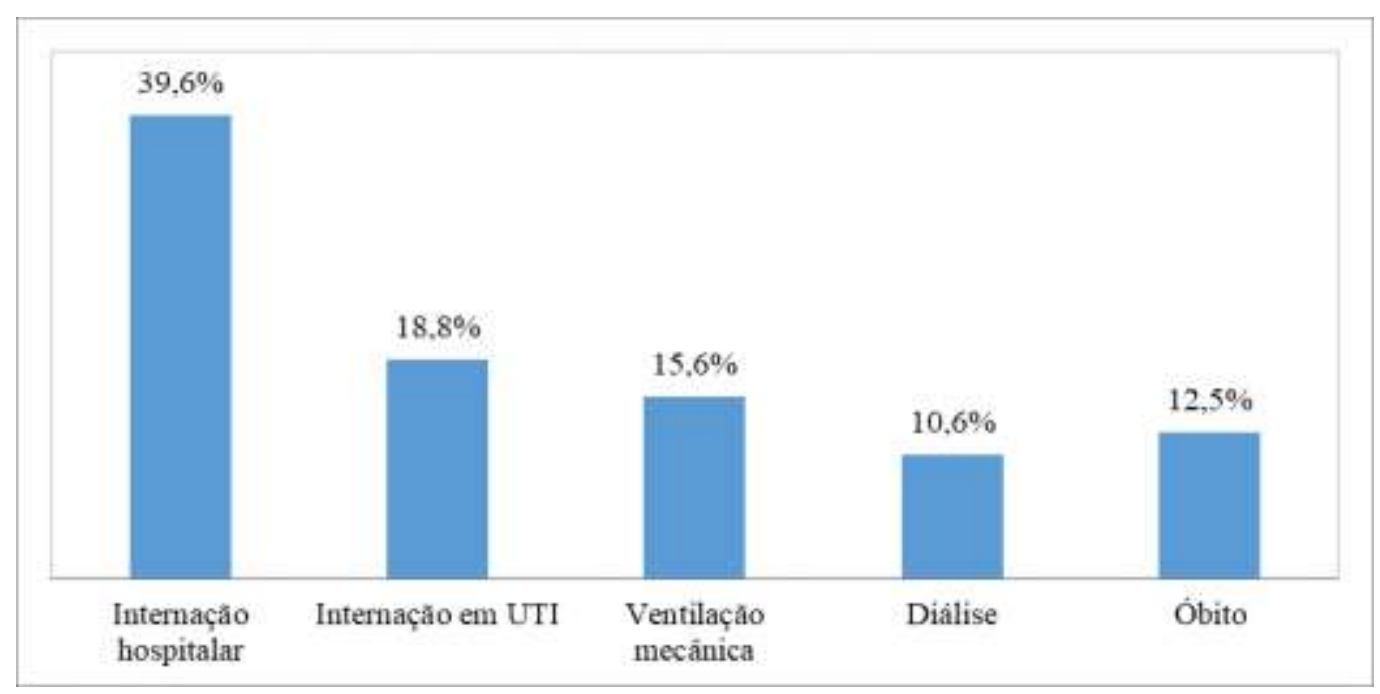

UTI: unidade de terapia intensiva. Fonte: Elaborada pelos autores.

A análise uni e multivariada dos fatores de risco associados ao óbito por COVID-19 estão demonstradas na Tabela 4. 
Tabela 4. Análise univariada das variáveis associadas ao maior risco de óbito por COVID-19 em receptores de transplante renal da população em estudo.

\begin{tabular}{|c|c|c|c|}
\hline Variável & Óbitos (n=12) & Sobreviventes $(n=84)$ & p \\
\hline Idade do receptor (anos)* & $61,2 \pm 15,4$ & $47,4 \pm 12,8$ & 0,001 \\
\hline Receptor masculino & $7(58,3 \%)$ & $46(54,8 \%)$ & 1,000 \\
\hline Tempo de transplante(anos)** & $13,99 \pm 10,58$ & $6,85 \pm 7,19$ & 0,012 \\
\hline Creat. basal (mg/dl)** & $1,86 \pm 1,25$ & $1,39 \pm 0,52$ & 0,248 \\
\hline Creat. COVID $(\mathrm{mg} / \mathrm{dl})^{* *}$ & $2,4 \pm 1,6$ & $1,7 \pm 0,8$ & 0,219 \\
\hline $\operatorname{IMC}\left(\mathrm{kg} / \mathrm{m}^{2}\right)^{*}$ & $26,3 \pm 6,1$ & $25,5 \pm 5,1$ & 0,631 \\
\hline Tipo de doador falecido & $10(83,3 \%)$ & $77(91,7 \%)$ & 0,313 \\
\hline Raça & & & 0,615 \\
\hline Branca & $4(33,3)$ & $16(19 \%)$ & \\
\hline Parda & $7(58,3 \%)$ & $58(69 \%)$ & \\
\hline Negra & $1(8,3 \%)$ & $6(7,1 \%)$ & \\
\hline Outras & - & $4(4,8 \%)$ & \\
\hline ISS com prednisona & $11(91,7 \%)$ & $56(66,7 \%)$ & 0,099 \\
\hline Tabagismo sim & $1(8,3 \%)$ & $23(27,4 \%)$ & 0,284 \\
\hline IECA/BRA sim & $4(33,3 \%)$ & $20(23,8 \%)$ & 0,487 \\
\hline Presença de comorbidades & $12(100 \%)$ & $74(88,1 \%)$ & 0,353 \\
\hline Hipertensão Arterial & $12(100,0 \%)$ & $61(72,6 \%)$ & 0,064 \\
\hline Diabetes Mellitus & $7(58,3 \%)$ & $29(34,5 \%)$ & 0,111 \\
\hline Doença cardiovascular & $5(41,7 \%)$ & $9(10,7 \%)$ & 0,004 \\
\hline Obesidade & $3(25,0 \%)$ & $16(19,0 \%)$ & 0,700 \\
\hline Neoplasia & $3(25,0 \%)$ & $9(10,7 \%)$ & 0,171 \\
\hline Outras & $10(83,3 \%)$ & $43(51,2 \%)$ & 0,060 \\
\hline Fonte de contágio nosocomial & $3(25,0 \%)$ & $6(7,1 \%)$ & 0,082 \\
\hline \multicolumn{4}{|l|}{ Tratamento COVID-19 } \\
\hline Dose alta esteroide & $10(83,3 \%)$ & $40(47,6 \%)$ & 0,029 \\
\hline Azitromicina & $12(100,0 \%)$ & $55(65,5 \%)$ & 0,016 \\
\hline Oseltamivir & $3(25,0 \%)$ & $7(8,3 \%)$ & 0,109 \\
\hline Hidroxicloroquina & $8(66,7 \%)$ & $10(11,9 \%)$ & 0,000 \\
\hline Ivermectina & $4(33,3 \%)$ & $31(36,9 \%)$ & 1,000 \\
\hline Heparina profilática & $7(58,3 \%)$ & $14(16,7 \%)$ & 0,004 \\
\hline Necessidade de internamento & $12(100 \%)$ & $26(31 \%)$ & 0,000 \\
\hline
\end{tabular}

* Teste t Student; **Teste de MannWhitney. Creat.: creatinina; IECA: inibidor da enzima de conversão da angiotensina; BRA: bloqueador do receptor da angiotensina; ISS: imunossupressão. Fonte: elaborada pelos autores

As seguintes variáveis foram incluídas no modelo multivariado: idade do receptor, creatinina basal do receptor, tempo de transplante, uso de esteroides na ISS, fonte de contágio, HAS e DCV (Tabela 5). 
Tabela 5. Análise multivariada das variáveis associadas ao maior risco de óbito por COVID-19 em receptores de transplante renal da população em estudo.

\begin{tabular}{lccc}
\hline Variável & $\operatorname{Exp}(\mathbf{B})$ & $\mathbf{9 5 \%}$ CI para $\operatorname{Exp}(\mathbf{B})$ & $\mathbf{p}$ \\
\hline $\begin{array}{l}\text { Idade do receptor em anos } \\
(>55 \text { v } \leq 55)\end{array}$ & 16,434 & $2,694-100,261$ & 0,002 \\
Tempo de transplante em anos & & & \\
$(>5,7 v s \leq 5,7)$ & 13,492 & $1,649-110,350$ & 0,015 \\
Creatinina basal (mg/dL) & 0,294 & $0,094-0,920$ & 0,035 \\
\hline
\end{tabular}

Fonte: Elaborada pelos autores.

\section{Discussão}

Desde dezembro de 2019, a comunidade científica vem debruçando seus esforços contra a pior epidemia da atualidade. Até março de 2020, o vírus já havia se disseminado por 203 países e foi oficialmente declarado estado de pandemia pela Organização Mundial da Saúde (OMS, 2020). Os fatores de risco mais importantes para mortalidade relacionada à COVID-19 são a idade avançada, doenças crônicas e comprometimento imunológico (Sohrabi et al., 2020). Diante deste novo desafio, os autores avaliam o impacto desta infecção entre os pacientes receptores de transplante renal de um único centro no Nordeste do Brasil, no curso da primeira onda da pandemia. A cidade onde o estudo foi realizado destaca-se por ter tido um curso grave e precoce da doença. Os primeiros casos de COVID-19 no Ceará foram confirmados em 15 de março de 2020, o isolamento social começou em Fortaleza em 19 de março de 2020 e o lockdown em 8 de maio de 2020, tendo sido a segunda capital brasileira a instalar o lockdown, que se manteve por 24 dias, até 01 de junho de 2020 (NORDESTE, 2020). Até 13/06/2020, a capital registrava 30.973 casos confirmados da doença e 2.848 óbitos.

Devido aos desafios impostos pela alta transmissão do vírus, desconhecimento da doença e riscos da mesma, o referido centro de transplante desenvolveu um meio de comunicação através de sistema de teleconsulta diária, onde os pacientes com quadro suspeito ou confirmado de COVID-19 eram avaliados e seguidos durante a doença por dois profissionais médicos da unidade, minimizando sua ida ao centro de transplante e ao mesmo tempo conseguindo monitorar e orientar esses pacientes, que conforme campanhas locais eram orientados a procurar as emergências da cidade para pronto atendimento. O quadro clínico, exames realizados e as condutas terapêuticas eram registradas em planilha padronizada.

Outros estudos em receptores de transplante renal evidenciaram de modo semelhante ao presente estudo uma maior prevalência da infecção por SARS-CoV-2 em receptores do gênero masculino (Azzi et al., 2020) (Hilbrands et al., 2021) enquanto Fang et al. (2020) citam que na população geral, a distribuição é similar entre os gêneros. Segundo dados da "European Renal Association COVID-19 Database", uma base de dados especificamente designada para coletar dados da COVID-19 em pacientes dialíticos ou receptores de transplante renal, entre 305 receptores de transplante renal desta base de dados, $62 \%$ eram do sexo masculino, com idade média de $60( \pm 13)$ anos (Hilbrands et al., 2021).

Recentemente, Kremer et al. (2021), publicaram uma revisão sistemática e metanálise sobre COVID-19 em transplante renal, e entre os 64 estudos incluídos, abrangendo um total de 5559 receptores de transplante renal com COVID-19, 64\% eram do sexo masculino, idade média de 58,2 anos e tempo médio após o transplante de 73 meses. Observa-se portanto, que em relação à idade, os pacientes do presente estudo são mais jovens do que os citados nos estudos acima (49,1 $\pm 13,8$ anos). Segundo Williamson et al. (2020), a idade e o sexo são fatores preditivos de ocorrência de formas graves de COVID-19 na população geral, sendo tal situação mais preponderante em indivíduos do sexo masculino ou idade superior a 60 anos. De acordo com Pollard et al. (2020), a idade foi o preditor mais significativo de desfecho desfavorável e associado à mortalidade.

Em relação às características raciais, a maior prevalência de pardos em nossa análise reflete as características do local da pesquisa, já que segundo o IBGE (2019), 67,7\% dos residentes da região nordeste do Brasil se autodeclararam pardos. 
Research, Society and Development, v. 11, n. 1, e34511125199, 2022

(CC BY 4.0) | ISSN 2525-3409 | DOI: http://dx.doi.org/10.33448/rsd-v11i1.25199

Ademais, o considerável risco de mortalidade em pacientes transplantados renais que contraíram COVID-19 se deve, consideravelmente, à presença de outras comorbidades apresentadas por esses indivíduos (Williamnson et al., 2020). No presente estudo, as comorbidades mais comuns foram a hipertensão arterial sistêmica (76\%), a diabetes mellitus (37,5\%), a obesidade (22,9\%) e as doenças cardiovasculares (14,6\%). Similarmente, Akalin et al. (2020), também em uma análise de centro único, observaram as mesmas comorbidades aqui destacadas, com percentuais ainda mais elevados (HAS em $94 \%$ dos pacientes, diabetes em 69\%, e doenças cardiovasculares em 17\%). O "TANGO International Transplant Consortium" identificou que entre 9845 receptores de transplante renal de 12 centros de transplantes de 3 países, 144 foram hospitalizados por COVID-19, sendo 66\% do sexo masculino, com uma idade média de $60( \pm 12)$ anos. As comorbidades mais prevalentes incluíam HAS (95\%), diabetes (52\%), obesidade (49\%), cardiopatias (28\%) e pneumopatias (19\%) (Cravedi et al., 2020). Da mesma forma, os dados da "European Renal Association COVID-19 Database" evidenciaram como principais comorbidades entre os receptores de transplante renal com COVID-19, a hipertensão arterial (83\%), diabetes mellitus (32\%), obesidade (23\%) e coronariopatia (21\%) (Hilbrands et al., 2020). É notório que tanto para pacientes não transplantados, quanto para transplantados renais, situações de hipertensão ou doença cardiovascular, acabam sendo fortes preditivas da mortalidade em casos de COVID-19 (Pereira et al., 2020) (Sharma et al., 2020).

É importante destacar que aspectos intrinsecamente relacionados aos hábitos de vida, como obesidade e tabagismo, já foram associados a pior prognóstico na COVID-19. No presente estudo, indivíduos obesos representavam 22,9\% e tabagistas abrangiam 25\% do montante analisado. Para Simonnet et al. (2020), a obesidade é um dos fatores determinantes para a intensa virulência do SARS-CoV-2 e consequentemente é responsável por uma maior mortalidade associada à doença. Assim, em pacientes obesos, os pools virais podem se alojar no tecido adiposo e promover a ativação imunológica e a liberação crônica excessiva de citocinas (Engin et al., 2020). Em relação ao tabagismo, apesar de uma mortalidade de fumantes ser 2,4 vezes superior em relação aos não fumantes (Vardavas et al., 2020), relatos como o de Simons et al. (2020) destacam a não observação de fatores que possam correlacionar tal hábito com agravos de saúde relativos à COVID-19.

$\mathrm{O}$ aumento da suscetibilidade à infecção por SARS-CoV-2 pode ser devido à regulação positiva do receptor da enzima conversora de angiotensina 2 (ACE2), o principal receptor usado pelo coronavírus (SARS-CoV-2) para entrar na mucosa do hospedeiro e causar infecção ativa (mecanismo aparentemente único para esse vírus). Os fumantes têm expressão gênica aumentada de ACE2, em relação aos ex-fumantes e não fumantes. Não está claro se a modificação da frequência ou disponibilidade do receptor ACE2 tem efeito sobre a mortalidade. Certamente, os pacientes em uso de inibidores da ECA (IECA) e bloqueadores do receptor da angiotensina 2 (BRA) não parecem ter risco aumentado de infecção ou morte. Atualmente, nenhuma evidência sugere que o uso de cigarro aumenta o risco de infecção por SARS-CoV-2 (Zyl-Smith et al., 2020). No presente estudo, porém, foi evidenciada uma baixa predominância de ambas as situações nos casos que resultaram em óbito, denotando não haver influência de tais fatores na coorte analisada.

Em relação às manifestações clínicas da COVID-19, a febre, a tosse e a mialgia, que foram os sintomas mais frequentes em nossa população, também foram os sintomas mais frequentes encontrados em outro estudo entre transplantados renais com COVID-19 (Akalin et al., 2020) enquanto que, em uma coorte de transplantados renais, os sintomas mais comuns foram a febre e dispneia, sendo nestes a frequência respiratória significativamente maior nos não-sobreviventes (Cravedi et al., 2020). Chen et al. (2020), estudando 249 indivíduos da população geral infectados pelo novo coronavírus, observaram como principais sintomas a febre $(87,1 \%)$, tosse $(36,5 \%)$ e fadiga $(15,7 \%)$. Dados europeus, demonstraram que os principais sintomas da COVID-19 em receptores de transplante renal foram febre (75\%), tosse (67\%), dispneia (46\%), mialgia e artralgia (28\%), enquanto no estudo do consórcio TANGO, os sintomas mais comuns na admissão foram febre e dispneia (67\%), seguido por mialgia (53\%) e diarreia (38\%) (Cravedi et al., 2020). 
Research, Society and Development, v. 11, n. 1, e34511125199, 2022

(CC BY 4.0) | ISSN 2525-3409 | DOI: http://dx.doi.org/10.33448/rsd-v11i1.25199

No presente estudo, o sintoma diarreia foi observado em $33 \%$ dos pacientes, uma prevalência semelhante ao estudo ERACODA (31\%) e TANGO (38,2\%) (Hilbrands et al., 2020) (Cravedi et al., 2020). Outros autores evidenciaram uma prevalência menor deste sintoma, sendo de $22 \%$ na análise de Akalin et al. (2020) e uma frequência significativamente mais baixa $(3,2 \%)$ no estudo de Chen et al. (2020). Em avaliação da população geral, Cummings et al. (2020) encontraram uma frequência de $12 \%$ de diarreia entre 40.000 indivíduos analisados.

A análise laboratorial na COVID-19 tem sido relacionada a fatores de gravidade da doença e de mortalidade. Nesse contexto, Cummings at al. (2020) relataram uma considerável frequência de proteinúria em exames de urina e de linfocitopenia, além da identificação de valores elevados de IL-6, proteína C reativa de alta sensibilidade, ferritina, D-dímero, troponina de alta sensibilidade e procalcitonina na maioria dos pacientes. Zhou et al. (2020), em Wuhan, detectaram linfocitopenia em $40 \%$ dos pacientes infectados e a contagem inicial de linfócitos foi significativamente maior nos sobreviventes do que naqueles não sobreviventes. Além disso, os níveis de D-dímero, troponina I cardíaca de alta sensibilidade, ferritina sérica, lactato desidrogenase e IL-6 foram claramente elevados em não sobreviventes quando comparado aos sobreviventes ao longo do curso clínico e estes níveis aumentaram com a deterioração da doença. Cravedi et al. (2020) destacam a presença de linfopenia em $42 \%$ dos transplantados renais infectados por COVID-19, mas não detectaram diferença estatisticamente significativa entre sobreviventes e não sobreviventes em termos de níveis de leucócitos, hemoglobina, plaquetas, alanina aminotransferase e creatinafosfoquinase. Em nossa análise, os pacientes que foram a óbito, tinham à admissão, menor contagem de linfócitos e níveis séricos aumentados de ferritina, fibrinogênio, D-dímero e proteína C reativa, além de maior comprometimento da função renal, com creatinina mais elevada.

O diagnóstico precoce na infecção por SARS-COV-2 é de extrema importância, pois além de monitorar o paciente, é possível através do isolamento do mesmo, interromper a cadeia de transmissão. Dessa forma, observa-se, predominantemente, tanto em nosso estudo quanto na literatura revisada, a aplicação da reação da transcriptase reversa seguida pela reação em cadeia da polimerase (RT-PCR) ou dos ensaios sorológicos de anticorpos IgA, IgG e IgM para fins de diagnóstico da COVID19. No nosso estudo, em $35 \%$ dos pacientes, o diagnóstico foi realizado através do RT-PCR, que atualmente é considerado o exame padrão-ouro para o diagnóstico e que quando realizado de maneira correta, no intervalo 3 a 10 dias após o início dos sintomas, possui alta sensibilidade e especificidade (Nogueira \& Silva, 2020). Apesar disso, segundo a Food and Drug Administration (2020), resultados negativos não excluem completamente a infecção por SARS-CoV-2, tendo a limitação de poder apresentar erros de sensibilidade devido a falhas de amostragem ou à carga viral insuficiente. Os demais pacientes, que corres

pondem a 65\% da nossa amostra, foram diagnosticados através da sorologia, que, segundo Xiang et al. (2020), em relação ao RT-PCR, costuma ser mais rápida, menos dispendiosa, fácil de usar e acessível à equipe sem treinamento laboratorial (Xiang et al., 2020). Convém ainda ressaltar que, diante da escassez de testes RT-PCR durante a realização de nosso estudo, a maioria dos diagnósticos não foi realizado através do exame considerado o padrão-ouro.

Ainda em relação a exames que auxiliam no diagnóstico e prognóstico dos pacientes com COVID-19, a tomografia computadorizada de tórax (TCAR) se mostrou de grande valia, demonstrando alterações típicas dessa infecção, além de mensurar o grau de acometimento pulmonar. A tomografia computadorizada (TC) tem sido relatada como uma ferramenta importante para identificar e investigar pacientes suspeitos com doença COVID-19 em estágio inicial (Alsharif \& Qurashi et al., 2021). Fang et al. (2020) relatam a alta sensibilidade da TC de tórax (98\%) em comparação com os testes RT-PCR (71\%). Ai et al. (2020) observaram uma sensibilidade de 97\% da TCAR para COVID-19, tendo como base os resultados positivos de RT-PCR. A alta sensibilidade e apresentação inicial na TC de tórax podem ser úteis na retificação de resultados falsos negativos obtidos de RT-PCR. No presente estudo, o vidro fosco foi a principal alteração detectada, seguida por consolidações. Os pacientes que tiveram sintomas moderados a graves foram submetidos ao exame de imagem, o que pode ter favorecido a 
alta prevalência de alterações na TCAR em nosso estudo (96,7\%), embora seja descrita a sua presença em casos assintomáticos e leves (Alsharif \& Qurashi, 2021). Em uma revisão sistemática incluindo 919 pacientes com diagnóstico confirmado de COVID-19, opacidades em vidro fosco foram relatadas como as anormalidades mais precoces, com uma taxa de ocorrência de até $88 \%$, enquanto consolidações foram descritas em aproximadamente 32\% dos pacientes (Pontone et al., 2021). Pan et al. (2020) identificaram que os principais achados tomográficos observados foram opacidade em vidro fosco, consolidações e pavimentação em mosaico, sendo destacável que o lobo inferior apresentava maior tendência de comprometimento, em uma análise dos achados da TCAR desde o diagnóstico inicial de COVID-19 até a recuperação total do paciente. Em receptores de transplante renal, as opacidades multifocais foram as alterações mais comuns (Elias et al., 2020) (Nair et al., 2020), sendo a sensibilidade em detectar as alterações maior nos pacientes que necessitaram de ventilação mecânica (92\%), do que naqueles que não necessitaram (60\%) (Elias et al., 2020). Segundo o consenso multinacional da Fleischner Society, três cenários principais onde a imagem pode ser usada como ferramenta diagnóstica primária foram identificados: pacientes com características respiratórias leves consistentes com COVID-19, mas com fatores de risco para progressão da doença; pacientes com características moderadas a graves de COVID-19, independentemente dos resultados do teste RT-PCR; e pacientes apresentando sintomas moderados a graves em uma alta prevalência da doença e com recursos de teste limitados (Rubin et al., 2020).

Sobre o manejo da imunossupressão (ISS) em receptores de transplante renal infectados por SARS-CoV-2 ainda há muitas dúvidas, havendo a preocupação com o aumento do risco de rejeição diante da suspensão ou redução das medicações em meio a uma doença pró-inflamatória, enquanto ao mesmo tempo a manutenção dessas medicações poderia diminuir a capacidade de resposta imune frente a formas graves da doença. Em nosso estudo, no momento do diagnóstico da COVID-19, o esquema imunossupressor mais utilizado foi o esquema tríplice com um antimetabólito, um inibidor de calcineurina e a prednisona. De um modo geral, a conduta diante do manejo da ISS foi moderada, uma vez que 40,6\% dos casos permaneceram com o mesmo regime imunossupressor e a principal alteração realizada, principalmente nos pacientes com sintomas mais importantes, foi a redução ou suspensão do antimetabólito (21,9\% e 29,2\% dos casos, respectivamente). Enquanto isso, $8,3 \%$ dos pacientes suspenderam completamente o esquema imunossupressor. Este manejo foi similar ao referido por outros autores, em que os pacientes também faziam uso, em sua maioria, da mesma associação de imunossupressores (Pereira et al., 2020) (Columbia University Kidney Transplant Program, 2020). No estudo multicêntrico brasileiro, ajustes dos medicamentos imunossupressores foram realizados em 74,4\% dos pacientes hospitalizados (Requião-Moura et al., 2020).

Cravedi et al. (2020), analisando receptores de transplante renal internados por COVID-19, registraram que o manejo mais frequente da ISS foi a suspensão do antimetabólito (67,9\%), seguido pela suspensão do tacrolimo (22,9\%), não havendo associação entre a mortalidade e a retirada da ISS. No estudo de Lubetzky et al. (2020), em que a taxa de letalidade geral foi de $13 \%$, destacou-se que, embora os ISS possam ter alguns reajustes durante o processo de infecção por COVID-19, de acordo com a gravidade da doença, a cessação completa da imunossupressão não se mostrou necessária para todos os receptores de transplante renal que foram infectados, como também foi observado em nossa análise. Nesse contexto, o autor expõe que entre os pacientes ambulatoriais, um terço teve a dose do micofenolato reduzida em $50 \%$ e não houve descontinuação do micofenolato, bem como não houve alteração da dose do tacrolimo nesse perfil de pacientes. Porém, até o momento, não há evidência do impacto da manutenção da imunossupressão nos casos de COVID-19 em transplantados renais e por isso não há um consenso do manejo entre as equipes assistentes.

Em relação ao manejo da COVID-19, dados nacionais multicêntricos, com grande número de receptores de transplante, revelaram que a principal conduta terapêutica foi a prescrição de antimicrobianos $(56,5 \%$ receberam azitromicina e 70,7\% receberam outros antibióticos que não azitromicina), aumento da dose de esteroide (43,6\%) e anticoagulantes (dose profilática em $29,5 \%$ dos hospitalizados e dose terapêutica em apenas 8,8\%), seguidos pelo antiviral oseltamivir (16,6\%) e 
Research, Society and Development, v. 11, n. 1, e34511125199, 2022

(CC BY 4.0) | ISSN 2525-3409 | DOI: http://dx.doi.org/10.33448/rsd-v11i1.25199

hidroxicloroquina/cloroquina (16,0\%; a maioria nos meses de março a abril de 2021) (Requião-Moura et al., 2020). Por sua vez, no presente estudo unicêntrico, as principais medicações utilizadas foram os antimicrobianos (azitromicina em 69,8\% e outros antibióticos em 34,4\%), esteroides em doses altas $(52,1 \%)$ e ivermectina $(36,5 \%)$. A hidroxicloroquina/cloroquina foi indicada em 18,8\% dos casos, o oseltamivir em 10,6\%, os anticoagulantes em dose profilática em 21,9\% e em dose plena em somente $4,2 \%$ dos pacientes. No estudo multicêntrico TANGO, com 144 receptores de transplante renal hospitalizados, as terapias indicadas foram: antibióticos (74,1\%), hidroxicloroquina (70,6\%), esteroides em doses altas (66\%), antivirais (14\%) e tocilizumab (13\%) (Cravedi et al., 2020).

Sabemos que uma parcela da população em geral, e mais expressivamente dos receptores de transplante renal, podem desenvolver a forma grave da doença, necessitando de internação hospitalar e, por vezes, suporte intensivo à saúde. Aproximadamente 5\% dos pacientes com COVID-19 e 20\% dos hospitalizados apresentam sintomas graves, necessitando de cuidados intensivos (Wiersinga et., 2020). Em estudo de coorte multicêntrico brasileiro, incluindo 1.680 receptores de 35 centros de transplante renal com diagnóstico de COVID-19 entre março e novembro de 2020, a taxa de hospitalização foi de $65,1 \%$, a de admissão em terapia intensiva foi de $34,6 \%$, sendo necessária ventilação mecânica em $24,9 \%$ dos casos. Injúria renal aguda foi detectada em 23,2\% dos pacientes e a taxa cumulativa de morte em 90 dias foi de $21 \%$ (Requião-Moura et al., 2021). No presente estudo unicêntrico, também brasileiro, a taxa de hospitalização foi inferior (39,5\%), bem como a de injúria renal aguda (10,6\% na população geral, mas 55,5\% dos internados em terapia intensiva) e de óbito (12,5\% da população geral). Esta diferença talvez possa ser atribuída a diferenças na política de saúde local ou efeito centro.

O envolvimento renal é frequente na COVID-19, com apresentação clínica variando de proteinúria anormal (mais de 40\% na admissão hospitalar) à injúria renal aguda (IRA) necessitando de terapia renal substitutiva, a qual é comum em pacientes com doença mais grave, afetando $20-40 \%$ dos pacientes internados em unidade de terapia intensiva (Richardson et al., 2020). A necessidade de terapia renal de substituição renal (TRS) ocorre em uma média de 15 dias a partir do início da doença, sendo um marcador de gravidade da doença é um fator de prognóstico negativo para sobrevida do paciente (Xiang et al., 2020). Especificamente na população de transplantados renais, a IRA é uma complicação frequente da COVID-19, sendo observada em 30\%-89\% dos receptores de transplante renal hospitalizados (Azzi et al., 2020). Vários fatores estão implicados na patogênese da IRA, incluindo redução da perfusão renal, insuficiência de múltiplos órgãos e tempestade de citocinas.

Por fim, no que concerne à observação da evolução a óbito em COVID-19, verificamos, em nossa análise, que tal desfecho negativo se fez presente em 12,5\% dos pacientes. Estudos que analisaram os receptores de transplantes renais internados por COVID-19 mostraram uma alta mortalidade, como Cravedi et al. (2020) que verificaram 32\% de mortalidade, muito similar à nossa pesquisa, que entre os internados detectou uma mortalidade de 31,5\%. No estudo de Hilbrands et al. (2021), a probabilidade de morte com 28 dias foi de 21,3\% (95\% CI 14,3-30,2\%) em receptores de transplante renal e 25,0\% (95\% CI 20,2-30,0\%) em pacientes em diálise. Williamson et al. (2020) revisaram 10.926 mortes relacionadas a SARS-CoV-2 e identificaram o transplante de órgãos como um fator de risco para mortalidade com uma razão de risco de 6,00. É possível que a menor mortalidade encontrada no presente estudo, deva-se ao fato de que o diagnóstico em um significativo percentual de pacientes foi realizado pelo quadro clínico e sorologia (RT-PCR à época ainda não era prontamente disponível na cidade) ou pelo monitoramento por teleconsulta diária de todos os pacientes com sintomas suspeitos, com orientação de cuidados na fase inicial e encaminhamento mais precoce para hospitalização. É possível ainda que casos mais graves em pacientes residindo em outros estados e seguidos em nosso centro não tenham entrado em contato, além do fato de que a população acometida tinha idade média abaixo de 50 anos e em torno de cinco anos de transplante, o que esteve associado a melhor prognóstico.

Além disso, no tocante à predição da mortalidade por COVID-19 entre os pacientes transplantados renais, observa-se comumente na literatura revisada o destaque para a idade dos pacientes, sendo tal desfecho mais comum em pacientes idosos 
(Cravedi et al., 2020) (Sánchez-Alvarez et al., 2020) (Caillard et al., 2020). Tal correspondência também se fez notável em nossa análise multivariada, em que o fator idade acima de 55 anos apresentou correlação com a predição de óbito $(\mathrm{OR}=16,43$, IC $95 \%$ 2,69-100,26; $\mathrm{p}=0,002)$.

Uma revisão sistemática de 26 estudos mostrou que idade superior a $60 \operatorname{anos}^{46}$, hipertensão, diabetes mellitus e doença coronariana são os fatores de risco para a forma grave de COVID-19. Os resultados dos testes laboratoriais associados à doença grave são LDH sérico 250-500 U / L, LDH > 500 U / L e linfopenia, enquanto os resultados dos testes associados à mortalidade são contagem de células CD3 $+\mathrm{CD} 8+\leq 75$ células / $\mu$, estágio 2 e 3 de injúria renal aguda, proteinúria $\geq 1+$, hematúria $\geq 1+$, dímero-D $>1 \mathrm{mg} / \mathrm{L}$ (Setiati et al., 2020).

Em um estudo de coorte observacional na região de Lombardia, Itália, incluindo 3988 pacientes com COVID-19 admitidos em terapia intensiva, os fatores de risco associados independentemente à mortalidade foram idade mais elevada, sexo masculino, elevada $\mathrm{FiO} 2$, pressão expiratória final positiva elevada, baixo índice de $\mathrm{O}_{2}$ na admissão, história de DPOC, hipercolesterolemia e diabetes tipo 2 (Grasselli et al., 2020). Uma meta-análise recente, com 45 estudos incluindo 18300 pacientes, sugere que a idade avançada e o diabetes estão associadas a um maior risco de mortalidade hospitalar em pacientes infectados pelo SARS-CoV-2, enquanto sexo masculino, hipertensão e tabagismo não se correlacionaram independentemente com o óbito (Silverio ela t., 2020).

O presente estudo encontrou ainda uma evidente correlação do tempo de transplante > 5,7 anos (OR=13,49, IC 95\% 1,65-110,35; p=0,015) com a ocorrência de óbitos na amostra analisada. No estudo multicêntrico brasileiro recentemente publicado, as variáveis relacionadas com a probabilidade de morte dentro de 90 dias após COVID-19 foram idade, tempo após o transplante, hipertensão arterial, doença cardiovascular prévia, uso de tacrolimo e micofenolato, uso recente de esteroides em altas doses e dispneia como sintoma do COVID-19 (Requião-Moura et al., 2021). Portanto, o maior tempo pós-transplante também associou-se à mortalidade. Neste caso, são pacientes com maior tempo de cumulativo de exposição à imunossupressão e, portanto maior chance de elevada carga viral ao contágio.

Enquanto isto, uma menor creatinina basal associou-se a uma proteção contra o óbito (OR=0,29, IC 95\% 0,09-0,92; $\mathrm{p}=0,035$ ) no presente estudo. Lopez et al. (2021), avaliando 53 receptores de transplante renal no sul da Espanha com COVID19, encontraram uma mortalidade de $19 \%$ e como fatores de risco para óbito além da idade do paciente e do tempo póstransplante, a função renal basal, da mesma forma que no presente estudo, a presença de pneumonia e a PCR mais elevada ao diagnóstico. Em contrapartida, na análise multivariada, fatores expressivamente descritos na literatura internacional tanto na população geral quanto de transplantes renais, a exemplo da proteína C-reativa superior a 10mg/L (Huang et al., 2020) não foram evidenciados como preditivos desse desfecho negativo em nossa população.

Foram limitações do presente estudo a ausência de confirmação diagnóstica da COVID-19 por RT-PCR em todos os pacientes, tendo sido aceito alterações tomográficas associadas à sorologia positiva, o número pequeno de pacientes e a análise conjunta de pacientes admitidos ao hospital e tratados a nível ambulatorial. É importante ressaltar ainda que estes resultados são da era pré-vacinação para COVID na população brasileira. Independente disto, a idade do receptor e o maior tempo de transplante estiveram presentes como associados ao maior risco de óbito.

\section{Conclusão}

A mortalidade por COVID-19 em receptores de transplante renal foi superior à da população geral, mas inferior ao descrito em outros centros de transplante. O tempo de transplante e a idade do receptor foram preditivos de óbito nesta população, enquanto uma menor creatinina basal associou-se à menor mortalidade. Estudos adicionais, prospectivos, realizados 
após melhor conhecimento da fisiopatologia da doença viral e dos testes diagnósticos são necessários para confirmar os resultados encontrados no presente estudo.

\section{Referências}

Ai, T., Yang, Z., Hou, H., Zhan, C., Chen, C., Lv, W., Tao, Q., Sun, Z., \& Xia, L. (2020). Correlation of Chest CT and RT-PCR Testing in Coronavirus Disease 2019 (COVID-19) in China: A Report of 1014 Cases. Radiology, 200642. https://doi.org/10.1148/radiol.2020200642

Akalin, E., Azzi, Y., Bartash, R., Seethamraju, H., Parides, M., Hemmige, V., Ross, M., Forest, S., Goldstein, Y. D., Ajaimy, M., Liriano-Ward, L., Pynadath, C., Loarte-Campos, P., Nandigam, P. B., Graham, J., Le, M., Rocca, J., \& Kinkhabwala, M. (2020). Covid-19 and Kidney Transplantation. New England Journal of Medicine, 382(25), 2475-2477. https://doi.org/10.1056/nejmc2011117

Alsharif, W., \& Qurashi, A. (2020). Effectiveness of COVID-19 diagnosis and management tools: A review. Radiography, 27(2). https://doi.org/10.1016/j.radi.2020.09.010

Azzi, Y., Bartash, R., Scalea, J., Loarte-Campos, P., \& Akalin, E. (2020). COVID-19 and Solid Organ Transplantation: A Review Article. Transplantation, 105(1), 37-55. https://doi.org/10.1097/tp.0000000000003523

Caillard, S., Anglicheau, D., Matignon, M., Durrbach, A., Greze, C., Frimat, L., Thaunat, O., Legris, T., Moal, V., Westeel, P. F., Kamar, N., Gatault, P., Snanoudj, R., Sicard, A., Bertrand, D., Colosio, C., Couzi, L., Chemouny, J. M., Masset, C., \& Blancho, G. (2020). An initial report from the French SOT COVID Registry suggests high mortality due to COVID-19 in recipients of kidney transplants. Kidney International, 98(6), 1549-1558. https://doi.org/10.1016/j.kint.2020.08.005

Chen, J., Qi, T., Liu, L., Ling, Y., Qian, Z., Li, T., Li, F., Xu, Q., Zhang, Y., Xu, S., Song, Z., Zeng, Y., Shen, Y., Shi, Y., Zhu, T., \& Lu, H. (2020). Clinical progression of patients with COVID-19 in Shanghai, China. Journal of Infection, 80(5), e1-e6. https://doi.org/10.1016/j.jinf.2020.03.004

Columbia University Kidney Transplant Program. (2020). Early Description of Coronavirus 2019 Disease in Kidney Transplant Recipients in New York. Journal of the American Society of Nephrology, 31(6), 1150-1156. https://doi.org/10.1681/asn.2020030375

Cravedi, P., Mothi, S. S., Azzi, Y., Haverly, M., Farouk, S. S., Pérez-Sáez, M. J., Redondo-Pachón, M. D., Murphy, B., Florman, S., Cyrino, L. G., Grafals, M., Venkataraman, S., Cheng, X. S., Wang, A. X., Zaza, G., Ranghino, A., Furian, L., Manrique, J., Maggiore, U., \& Gandolfini, I. (2020). COVID-19 and kidney transplantation: Results from the TANGO International Transplant Consortium. American Journal of Transplantation. https://doi.org/10.1111/ajt.16185

Cummings, M. J., Baldwin, M. R., Abrams, D., Jacobson, S. D., Meyer, B. J., Balough, E. M., Aaron, J. G., Claassen, J., Rabbani, L. E., Hastie, J., Hochman, B. R., Salazar-Schicchi, J., Yip, N. H., Brodie, D., \& O’Donnell, M. R. (2020). Epidemiology, clinical course, and outcomes of critically ill adults with COVID-19 in New York City: a prospective cohort study. The Lancet, 395(10239), 1763-1770. https://doi.org/10.1016/s0140-6736(20)31189-2

Elias, M., Pievani, D., Randoux, C., Louis, K., Denis, B., Delion, A., Goff, O. L., Antoine, C., Greze, C., Pillebout, E., Abboud, I., Glotz, D., Daugas, E., \& Lefaucheur, C. (2020). COVID-19 Infection in Kidney Transplant Recipients: Disease Incidence and Clinical Outcomes. Journal of the American Society of Nephrology, 31(10), 2413-2423. https://doi.org/10.1681/ASN.2020050639

Engin, A. B., Engin, E. D., \& Engin, A. (2020). Two important controversial risk factors in SARS-CoV-2 infection: Obesity and smoking. Environmental Toxicology and Pharmacology, 78, 103411. https://doi.org/10.1016/j.etap.2020.103411

FACT SHEET FOR HEALTHCARE PROVIDERS New York SARS-CoV-2 Real-time RT-PCR Diagnostic Panel. (2020). https://www.fda.gov/media/135662/download

Fang, Y., Zhang, H., Xie, J., Lin, M., Ying, L., Pang, P., \& Ji, W. (2020). Sensitivity of Chest CT for COVID-19: Comparison to RT-PCR. Radiology, 296(2), 200432. https://doi.org/10.1148/radiol.2020200432

González, J., \& Ciancio, G. (2020). Early experience with COVID-19 in kidney transplantation recipients: update and review. International Braz J Urol, 46(suppl 1), 145-155. https://doi.org/10.1590/s1677-5538.ibju.2020.s114

Grasselli, G., Greco, M., Zanella, A., Albano, G., Antonelli, M., Bellani, G., Bonanomi, E., Cabrini, L., Carlesso, E., Castelli, G., Cattaneo, S., Cereda, D., Colombo, S., Coluccello, A., Crescini, G., Forastieri Molinari, A., Foti, G., Fumagalli, R., Iotti, G. A., \& Langer, T. (2020). Risk Factors Associated With Mortality Among Patients With COVID-19 in Intensive Care Units in Lombardy, Italy. JAMA Internal Medicine, 180(10), 1345. https://doi.org/10.1001/jamainternmed.2020.3539

Hilbrands, L. B., Duivenvoorden, R., Vart, P., Franssen, C. F. M., Hemmelder, M. H., Jager, K. J., Kieneker, L. M., Noordzij, M., Pena, M. J., Vries, H. de, Arroyo, D., Covic, A., Crespo, M., Goffin, E., Islam, M., Massy, Z. A., Montero, N., Oliveira, J. P., Roca Muñoz, A., \& Sanchez, J. E. (2021). Erratum to: COVID-19-related mortality in kidney transplant and dialysis patients: results of the ERACODA collaboration. Nephrology Dialysis Transplantation, 36(10), 1962-1962. https://doi.org/10.1093/ndt/gfab028

Huang, I., Pranata, R., Lim, M. A., Oehadian, A., \& Alisjahbana, B. (2020). C-reactive protein, procalcitonin, D-dimer, and ferritin in severe coronavirus disease-2019: a meta-analysis. Therapeutic Advances in Respiratory Disease, 14, 175346662093717. https://doi.org/10.1177/1753466620937175

IBGE | Portal do IBGE | IBGE. (2019). Www.ibge.gov.br. http://www.ibge.gov.br

Kremer, D., Pieters, T. T., Verhaar, M. C., Berger, S. P., Bakker, S. J. L., Zuilen, A. D., Joles, J. A., Vernooij, R. W. M., \& Balkom, B. W. M. (2021). A systematic review and meta-analysis of COVID-19 in kidney transplant recipients: Lessons to be learned. American Journal of Transplantation. https://doi.org/10.1111/ajt.16742 
Lopez, V., Casas-González, C., Vázquez, T., Cabello, M., Poveda, I., \& Hernández, D. (2021). Predictors of mortality in kidney transplant patients infected by sars-cov-2 in south of Spain. Nephrology Dialysis Transplantation, 36(Supplement_1). https://doi.org/10.1093/ndt/gfab110.0053

Lubetzky, M., Aull, M. J., Craig-Schapiro, R., Lee, J. R., Marku-Podvorica, J., Salinas, T., Gingras, L., Lee, J. B., Sultan, S., Kodiyanplakkal, R. P., Hartono, C., Saal, S., Muthukumar, T., Kapur, S., Suthanthiran, M., \& Dadhania, D. M. (2020). Kidney allograft recipients, immunosuppression, and coronavirus disease-2019: a report of consecutive cases from a New York City transplant center. Nephrology, Dialysis, Transplantation: Official Publication of the European Dialysis and Transplant Association - European Renal Association, 35(7), 1250-1261. https://doi.org/10.1093/ndt/gfaa154

Mitchell, C., \& https://www.facebook.com/pahowho. (2020, March 11). PAHO/WHO|WHO characterizes COVID-19 as a pandemic. Pan American Health Organization / World Health Organization. https://www.paho.org/hq/index.php?option=com_content\&view=article\&id=15756: who-characterizes-covid-19-asa-pandemic\&Itemid=1926\&lang=en

Nair, V., Jandovitz, N., Hirsch, J. S., Nair, G., Abate, M., Bhaskaran, M., Grodstein, E., Berlinrut, I., Hirschwerk, D., Cohen, S. L., Davidson, K. W., Dominello, A. J., Osorio, G. A., Richardson, S., Teperman, L. W., \& Molmenti, E. P. (2020). COVID-19 in kidney transplant recipients. American Journal of Transplantation, 20(7), 1819-1825. https://doi.org/10.1111/ajt.15967

Nogueira, J. M. da R., \& Silva, L. O. P. da. (2020). Diagnóstico laboratorial da COVID-19 no Brasil. Revista Brasileira de Análises Clínicas, 52(2). https://doi.org/10.21877/2448-3877.20200007

Nordeste, D. jornal O. P. para a R. (2021, March 11). Ceará todo entra em lockdown geral e simultâneo pela primeira vez. JC. https://jc.ne10.uol.com.br/brasil/2021/03/12039422-governador-do-ceara-decreta-lockdown-em-todo-o-estado-a-partir-de-sabado.html

Pan, F., Ye, T., Sun, P., Gui, S., Liang, B., Li, L., Zheng, D., Wang, J., Hesketh, R. L., Yang, L., \& Zheng, C. (2020). Time Course of Lung Changes On Chest CT During Recovery From 2019 Novel Coronavirus (COVID-19) Pneumonia. Radiology, 200370. https://doi.org/10.1148/radiol.2020200370

Pêgo-Fernandes, P. M., Pestana, J. O. M., Garcia, V. D., Pêgo-Fernandes, P. M., Pestana, J. O. M., \& Garcia, V. D. (2019). Transplants in Brazil: where are we? Clinics, 74. https://doi.org/10.6061/clinics/2019/e832

Pereira, M. R., Mohan, S., Cohen, D. J., Husain, S. A., Dube, G. K., Ratner, L. E., Arcasoy, S., Aversa, M. M., Benvenuto, L. J., Dadhania, D. M., Kapur, S., Dove, L. M., Brown, R. S., Rosenblatt, R. E., Samstein, B., Uriel, N., Farr, M. A., Satlin, M., Small, C. B., \& Walsh, T. J. (2020). COVID-19 in solid organ transplant recipients: Initial report from the US epicenter. American Journal of Transplantation, 20(7), 1800-1808. https://doi.org/10.1111/ajt.15941

Pollard, C. A., Morran, M. P., \& Nestor-Kalinoski, A. L. (2020). The COVID-19 Pandemic: A Global Health Crisis. Physiological Genomics, 52(11). https://doi.org/10.1152/physiolgenomics.00089.2020

Pontone, G., Scafuri, S., Mancini, M. E., Agalbato, C., Guglielmo, M., Baggiano, A., Muscogiuri, G., Fusini, L., Andreini, D., Mushtaq, S., Conte, E., Annoni, A., Formenti, A., Gennari, A. G., Guaricci, A. I., Rabbat, M. R., Pompilio, G., Pepi, M., \& Rossi, A. (2021). Role of computed tomography in COVID-19. Journal of Cardiovascular Computed Tomography, 15(1), 27-36. https://doi.org/10.1016/j.jcct.2020.08.013

Requião-Moura, L. R., Sandes-Freitas, T. V. de, Viana, L. A., Cristelli, M. P., Andrade, L. G. M. de, Garcia, V. D., Oliveira, C. M. C. de, Esmeraldo, R. de M., Abbud Filho, M., Pacheco-Silva, A., Sousa, K. C., Vicari, A. R., Costa, K. M. A. H., Simão, D. R., Sousa, M. V. de, Campos, J. B., Almeida, R. A. M. de B., Deboni, L. M., Neto, M. M., \& Zanocco, J. A. (2021). High mortality among kidney transplant recipients diagnosed with coronavirus disease 2019: Results from the Brazilian multicenter cohort study. PLOS ONE, 16(7), e0254822. https://doi.org/10.1371/journal.pone.0254822

Richardson, S., Hirsch, J. S., Narasimhan, M., Crawford, J. M., McGinn, T., Davidson, K. W., Barnaby, D. P., Becker, L. B., Chelico, J. D., Cohen, S. L., Cookingham, J., Coppa, K., Diefenbach, M. A., Dominello, A. J., Duer-Hefele, J., Falzon, L., Gitlin, J., Hajizadeh, N., Harvin, T. G., \& Hirschwerk, D. A. (2020). Presenting Characteristics, Comorbidities, and Outcomes Among 5700 Patients Hospitalized with COVID-19 in the New York City Area. JAMA, 323(20). https://doi.org/10.1001/jama.2020.6775

Rubin, G. D., Ryerson, C. J., Haramati, L. B., Sverzellati, N., Kanne, J. P., Raoof, S., Schluger, N. W., Volpi, A., Yim, J.-J., Martin, I. B. K., Anderson, D. J., Kong, C., Altes, T., Bush, A., Desai, S. R., Goldin, J., Goo, J. M., Humbert, M., Inoue, Y., \& Kauczor, H.-U. (2020). The Role of Chest Imaging in Patient Management During the COVID-19 Pandemic. Chest, 158(1), 106-116. https://doi.org/10.1016/j.chest.2020.04.003

Sánchez-Álvarez, J. E., Pérez Fontán, M., Jiménez Martín, C., Blasco Pelícano, M., Cabezas Reina, C. J., Sevillano Prieto, Á. M., Melilli, E., Crespo Barrios, M., Macía Heras, M., \& del Pino y Pino, M. D. (2020). Situación de la infección por SARS-CoV-2 en pacientes en tratamiento renal sustitutivo. Informe del Registro COVID-19 de la Sociedad Española de Nefrología (SEN). Nefrología, 40(3), 272-278. https://doi.org/10.1016/j.nefro.2020.04.002

Sharma, P., Chen, V., Fung, C. M., Troost, J. P., Patel, V. N., Combs, M., Norman, S., Garg, P., Colvin, M., Aaronson, K., Sonnenday, C. J., Golob, J. L., Somers, E. C., \& Doshi, M. M. (2020). COVID-19 Outcomes Among Solid Organ Transplant Recipients: A Case-Control Study. Transplantation, Online First. https://doi.org/10.1097/TP.0000000000003447

Silverio, A., Di Maio, M., Citro, R., Esposito, L., Iuliano, G., Bellino, M., Baldi, C., De Luca, G., Ciccarelli, M., Vecchione, C., \& Galasso, G. (2021). Cardiovascular risk factors and mortality in hospitalized patients with COVID-19: systematic review and meta-analysis of 45 studies and 18,300 patients. BMC Cardiovascular Disorders, 21(1). https://doi.org/10.1186/s12872-020-01816-3

Simonnet, A., Chetboun, M., Poissy, J., Raverdy, V., Noulette, J., Duhamel, A., Labreuche, J., Mathieu, D., Pattou, F., Jourdain, M., \& Lille Intensive Care COVID-19 and Obesity study group. (2020). High prevalence of obesity in severe acute respiratory syndrome coronavirus-2 (SARS-CoV-2) requiring invasive mechanical ventilation. Obesity (Silver Spring, Md.), 28(7). https://doi.org/10.1002/oby.22831

Simons, D., Shahab, L., Brown, J., \& Perski, O. (2020). The association of smoking status with SARS-CoV-2 infection, hospitalization and mortality from COVID-19: a living rapid evidence review with Bayesian meta-analyses (version 7). Addiction, 116(6), 1319-1368. https://doi.org/10.1111/add.15276

Sohrabi, C., Alsafi, Z., O’Neill, N., Khan, M., Kerwan, A., Al-Jabir, A., Iosifidis, C., \& Agha, R. (2020). World Health Organization declares Global Emergency: A review of the 2019 Novel Coronavirus (COVID-19). International Journal of Surgery, 76. https://doi.org/10.1016/j.ijsu.2020.02.034

Vardavas, C., \& Nikitara, K. (2020). COVID-19 and smoking: A systematic review of the evidence. Tobacco Induced Diseases, 18(March). 
Research, Society and Development, v. 11, n. 1, e34511125199, 2022

(CC BY 4.0) | ISSN 2525-3409 | DOI: http://dx.doi.org/10.33448/rsd-v11i1.25199

https://doi.org/10.18332/tid/119324

Vistoli, F., Furian, L., Maggiore, U., Caldara, R., Cantaluppi, V., Ferraresso, M., Zaza, G., Cardillo, M., Biancofiore, G., Menichetti, F., Russo, A., Turillazzi, E., Di Paolo, M., Grandaliano, G., \& Boggi, U. (2020). COVID-19 and kidney transplantation: an Italian Survey and Consensus. Journal of Nephrology. https://doi.org/10.1007/s40620-020-00755-8

Voora, S., \& Adey, D. B. (2019). Management of Kidney Transplant Recipients by General Nephrologists: Core Curriculum 2019. American Journal of Kidney Diseases, 73(6), 866-879. https://doi.org/10.1053/j.ajkd.2019.01.031

Wang, D., Hu, B., Hu, C., Zhu, F., Liu, X., Zhang, J., Wang, B., Xiang, H., Cheng, Z., Xiong, Y., Zhao, Y., Li, Y., Wang, X., \& Peng, Z. (2020). Clinical Characteristics of 138 Hospitalized Patients with 2019 Novel Coronavirus-Infected Pneumonia in Wuhan, China. JAMA, 323(11), 1061-1069. https://doi.org/10.1001/jama.2020.1585

WHO. (2020, July 31). Coronavirus Disease (COVID-19) - Events as They Happen. Www.who.int. https://www.who.int/emergencies/diseases/novelcoronavirus-2019/events-as-they-happen

Wiersinga, W. J., Rhodes, A., Cheng, A. C., Peacock, S. J., \& Prescott, H. C. (2020). Pathophysiology, Transmission, Diagnosis, and Treatment of Coronavirus Disease 2019 (COVID-19): A Review. JAMA, 324(8). https://doi.org/10.1001/jama.2020.12839

Williamson, E. J., Walker, A. J., Bhaskaran, K., Bacon, S., Bates, C., Morton, C. E., Curtis, H. J., Mehrkar, A., Evans, D., Inglesby, P., Cockburn, J., McDonald, H. I., MacKenna, B., Tomlinson, L., Douglas, I. J., Rentsch, C. T., Mathur, R., Wong, A. Y. S., Grieve, R., \& Harrison, D. (2020). OpenSAFELY: factors associated with COVID-19 death in 17 million patients. Nature. https://doi.org/10.1038/s41586-020-2521-4

Xiang, F., Wang, X., He, X., Peng, Z., Yang, B., Zhang, J., Zhou, Q., Ye, H., Ma, Y., Li, H., Wei, X., Cai, P., \& Ma, W.-L. (2020). Antibody Detection and Dynamic Characteristics in Patients With Coronavirus Disease 2019. Clinical Infectious Diseases. https://doi.org/10.1093/cid/ciaa461

Zhou, F., Yu, T., Du, R., Fan, G., Liu, Y., Liu, Z., Xiang, J., Wang, Y., Song, B., Gu, X., Guan, L., Wei, Y., Li, H., Wu, X., Xu, J., Tu, S., Zhang, Y., Chen, H., \& Cao, B. (2020). Clinical course and risk factors for mortality of adult inpatients with COVID-19 in Wuhan, China: a retrospective cohort study. The Lancet, 395(10229). https://doi.org/10.1016/s0140-6736(20)30566-3

Zyl-Smit, R. N. van, Richards, G., \& Leone, F. T. (2020). Tobacco smoking and COVID-19 infection. The Lancet Respiratory Medicine, O(0). https://doi.org/10.1016/S2213-2600(20)30239-3 